\title{
ADMINISTRACION UNIVERSITARIA Y GESTIÓN PRESUPUESTAL
}

Dra. Beatriz Herrera García*

\begin{abstract}
RESUMEN
La trascendencia que la ciencia y la técnica tienen para la sociedad actual, la demanda para un número cada vez mayor de especialistas e investigadores, la conciencia de que nuestro futuro depende en gran parte de ellos, de su número y calidad. La nueva universidad ha de formar a un número cada vez mayor de especialistas de las más diversas clases, que han de enfrentarse con un mundo en continua evolución y no vivir en los caminos trillados del profesionalismo de antaño.

La universidad aparece como una de las fuerzas que coopera con este fin común y sus tareas se integran dentro de unos proyectos generales de investigación y enseñanza. No es posible ya analizar la universidad como ente aislado, sino en conexión con el conjunto del sistema de educación y de progreso de un país. Esa preocupación de los problemas nacionales propia de la universidad actual no debe hacer olvidar que hoy no es posible pensar en educar solo a escala nacional, la universidad no puede desconocer esta realidad.

En consecuencia, las dos tareas fundamentales de la universidad siguen siendo hoy, la educación y el avance del saber, lo que cambia es la perspectiva en que se sitúan esas dos misiones. Ambas son ahora tareas nacionales, la universidad está ligada a esa misión y en ella ha de encuadrar sus actividades.
\end{abstract}

\section{INTRODUCCIÓN}

La manera como se asigna el presupuesto hacia las universidades ha ido cambiando; desde una época en que se asignaba a partir del número de matriculados hasta la fecha en que la evaluación de todos los procesos académicos es la base de un sistema de asignación de recursos. Por otro lado, el subsidio directo a las universidades públicas está dejando de ser considerado por el gobierno como la vía privilegiada, la gratuidad constitucional ya no es considerada como criterio para la asignación de recursos; en cambio se estima que las universidades son "empresas" que venden servicios educativos que los individuos aprovechan y por lo tanto deben pagarlas. El recorte presupuestal progresivo es la técnica que intenta facilitar la operación del nuevo dispositivo de regulación, basado en la evaluación del desempeño de las instituciones, provocando la diversificación de sus fuentes de financiamiento que contempla a su vez la elevación de las tasas y cobros de sus servicios.

Al menos son dos los modelos conceptualizados sobre la educación pública que se enfrentan violentamente, pero que en lo cotidiano son sus alcances los que muestran

* Profesora Principal y Vicerrectora Administrativa de la UNMSM 
sus límites y repercusiones. Uno es el que considera la educación como un bien social y sostiene que el Estado debe financiarla para facilitar la equidad y la igualdad de oportunidades para estudiantes de bajos ingresos; en el otro, se considera la educación como una inversión que deben hacer los estudiantes y sus familias en forma directa porque los.beneficia a ellos.

La defensa de la educación pública gira en torno al respeto, al derecho a la educación y al cumplimiento de los gobiernos en la prestación del servicio público de acuerdo con la demanda educativa.

La Universidad Nacional Mayor de San Marcos tiene la mayor cobertura de la demanda, esto quiere decir que es la institución universitaria más solicitada por la mayoría de los jóvenes que están en edades de cursar el nivel superior de educación, dentro de otras opciones. Además de ser una institución de educación pública hecho que es confirmado por la composición socioeconómica de la comunidad estudiantil, la cual en no menos del 60 por ciento es de escasos recursos, la posición que tiene en relación al resto del sistema universitario tanto público como privado le imprime un carácter único; éste es el gran sentido de servicio a la sociedad.

Desgraciadamente, como lo hemos expresado, todas las autoridades administrativas, la falta de presupuesto (cada vez más insuficiente), la forma carente de criterios y desigual con que se los distribuye impide a ésta responder a la demanda educativa, a la calidad y competitividad; aún así con carencias, a parte de su cobertura, la UNMSM concentra también una gran mayoría de los investigadores calificados que hay en el sistema universitario público.

Estado está obligado a otorgarle sin condicionamientos los recursos que requiere la universidad pública para que ésta preste a la población sus servicios educativos. Lo alarmante es que a causa de una infraestructura que no ha crecido al mismo ritmo que la demanda educativa y a un presupuesto raquítico, las universidades, y entre ellas la nuestra, están decidiendo no aumentar más las vacantes en respuesta a tal situación.

En los años 1999, 2000 y 2001 las vacantes en la UNMSM han sido 7146 , 6445 y 5542 , respectivamente $y$, por otro lado, los postulantes han sido 55,586; 66,392 ; y 60,394; respectivamente, es decir, las tendencias de uno y otro fueron asimétricas por lo que el saldo de los miles de rechazados puede relacionarse con la llamada racionalización de los recursos presupuestales.

Sin embargo, la recuperación de la universidad y la vuelta de la democracia genera enormes expectativas de la comunidad universitaria para contraponerse al cumplimiento a las condicionantes que empezaban a figurar como criterios en la asignación del presupuesto y a la vez como dispositivos de control de la creciente demanda educativa, en nombre de la llamada "excelencia", "calidad" y demás historias que tenían caracteres principalmente de tipo socioeconómico para negar el derecho a la educación.

\section{LAS PRIMERAS UNIVERSIDADES}

En tiempos de Grecia y Roma se formaron una muy buena base de educación, saber e investigación, con maestros y alumnos. Fue la época de los grandes eruditos, de las grandes escuelas y liceos, de los grandes sabios como Aristóteles y Platón, que sin existir el término universidad supieron forjar una excelente masa de conocimientos que hasta nuestros días influyen. 
La universidad es una institución de larga y compleja historia, que ofrece facetas diversas según las épocas y los países. Sirve a la vez a distintos fines que no siempre es fácil reducir a una idea central

Así, la Universidad Imperial fue una de las tantas universidades que tuvo influencia de la famosa ordenación napoleónica; tenía un concepto distinto de la que comúnmente se podría denominar universidad. Era más bien un organismo estatal al servicio del Estado. Francia y los países que lo imitaron resolvieron el problema de la universidad por el camino de suprimirlas en su forma tradicional y organizar en forma distinta la enseñanza superior, aplicando un nuevo sistema relacionado al estado centralista y burocrático que surge con la revolución. A principios del Siglo XIX se produce también un movimiento de reformas de las universidades de Oxford y Cambridge, únicas universidades inglesas entonces existentes. En Alemania el movimiento renovado provoca la fundación de la Universidad de Berlín, en 1810, que inicia la nueva era de la Universidad Germánica.

La Universidad Inglesa, la Universidad Alemana y la crisis de la primera posguerra inspiran la mediación de quienes buscan la idea de la universidad. De ella saldrán algunos estudios fundamentales a los cuales será necesario hacer referencia. Cuando en 1800, la Universidad de Oxford reformó su sistema de exámenes para alcanzar el grado de bachelor of arts (comprendía tres pruebas, una de religión, otra de cultura clásica y lengua, y una tercera de matemáticas y ciencias físicas). Contra ese sistema se alzaron voces de los que propugnaban una rigurosa especialización profesional. Contra esa posición surgió la defensa del sistema de Oxford concebido con un espíritu de "educación liberal", que es el conjunto de conocimientos y la disciplina intelectual que un hombre ha de tener como tal, con independencia de su concreta actividad profesional o de su especialización. No es un medio para alcanzar fines, sino que es un fin en sí misma, que tiene un fin tangible, real e idóneo.

En ese sentido Newman sostenía que la investigación no es uno de los fines esenciales de la universidad, tampoco lo es la formación de científicos. Ha de basarse precisamente en la idea de la "unidad del conocimiento", es decir, en la idea de que todas las ramas del saber están entre sí en intima relación, porque son en realidad parte de un todo. El fin de la educación liberal es la formación intelectual del estudiante, su misión es conferirle unos hábitos y unos modos de pensar que dilaten su horizonte espiritual y disciplinen y ordenen su capacidad de juicio y el ejercicio de su inteligencia. Esa formación intelectual va dirigida a su vez, a modelar un tipo humano determinado. Para lograr esos fines la universidad ha de convertirse en imperio del saber y la cultura donde reine un ambiente mutuo de intercambio de ideas $y$ en el cual se discutan el ámbito y la función de cada rama de la ciencia y sus relaciones recíprocas.

La moderna Universidad Alemana surge con el Estado Prusiano en 1810, con la fundación de la Universidad de Berlín. La universidad era una corporación al servicio de la ciencia. Ciencia e investigación serán la clave de la idea alemana de la Universidad. Según Jaspers, su misión consistía en buscar y trasmitir la verdad por medio de la ciencia. Esta reflexión se centra en la naturaleza de la ciencia como esencia misma de la universidad.

La investigación constituye la tarea primordial de la universidad, la ciencia y la investigación exigen como condición indispensable que pueda existir una libre búsqueda de la verdad. La libertad espiritual constituye así una consecuencia forzosa del fundamento necesario de la vida universitaria. De esta idea central de la universidad al servicio de la ciencia nace también 
el punto de vista respecto a la enseñanza y a la formación universitaria. La enseñanza se centra en la base científica que han de recibir los estudiantes. Jaspers rechaza la posibilidad de la existencia de un ideal formativo que trascienda el nivel intelectual. La universidad sólo puede dar una formación científica.

La crítica de Ortega y Gasset, acerca del modelo alemán, es que la misión de la universidad no es el cultivo de la ciencia, sino formar hombres cultos, trasmitir y elaborar la cultura. En ese sentido la cultura es el sistema de ideas vivas que cada tiempo posee, el sistema de ideas desde los cuales el tiempo vive. La cultura, por lo tanto, no se presenta en la exposición de Ortega como una suma de conocimientos, sino como un conjunto de ideas vitales, ideas que guían la existencia humana y justifican las decisiones que en cada momento adopta el hombre. Pero ciencia e investigación deben ocupar una zona circular a la universidad y no intentar absorber su centro ni usurpar la auténtica misión de ésta que es la cultura.

En cambio, la idea de la universidad americana no es la de una comunidad por un principio único. La universidad actual y sobre todo la del futuro está condicionada por un conjunto de factores que la diferencian de lo que fue la universidad decimonónica. Hoy asistimos a la llamada masificación de la universidad, de grupos cada vez más numerosos que acuden a las puertas de la universidad, como consecuencia de la democratización de la enseñanza. Ellos plantean ingentes problemas materiales (edificios, profesores, laboratorios, residencias, comedores, etc.); pero, además le imprimen un nuevo tono a la universidad.

La trascendencia que la ciencia y la técnica tiene para la sociedad actual, la demanda para un número cada vez mayor de especialistas e investigadores, la conciencia de que nuestro futuro depende en gran parte de ellos, de su número y de su calidad. La nueva universidad ha de formar un número cada vez mayor de especialistas y técnicos de la más diversa clase, quienes han de enfrentarse con un mundo en continua evolución y no vivir en los caminos trillados del profesionalismo de antaño.

La universidad aparece como una de las fuerzas que ha de cooperar con este fin común y sus tareas se integran dentro de unos proyectos generales de investigación y enseñanza. No es posible ya analizar la universidad como un ente aislado, sino en conexión con el conjunto del sistema educativo, de progreso y técnico de un país. Esa preocupación de los problemas nacionales, propia de la universidad actual, no debe hacer olvidar que hoy no es posible pensar o educar sólo a escala nacional, la universidad no puede desconocer esta realidad.

Las dos tareas fundamentales de la universidad siguen siendo la educación y el avance del saber, lo que cambia es la perspectiva en que se sitúan esas dos misiones.

\section{LA NATURALEZA DEL PRESUPUESTO}

Actualmente los presupuestos consisten en una Ley que recoge la totalidad de gastos e ingresos del Estado previstos para cada año, y mediante la cual el legislador autoriza a las diferentes administraciones estatales para realizar dichos gastos, con los límites y el destino en ella especificados.

Al presupuesto se le dota de un fuerte significado político, por un lado, porque a través de él se manifiesta el predominio de la voluntad general, expresado en la aprobación parlamentaria de las decisiones fundamentales de la hacienda pública; por el otro, porque mediante la aprobación del presupuesto y las limitaciones que encierra para el ejecutivo se está arbitrando un 
control riguroso y detallado de la actuación de éste, en beneficio del imperio de la ley y en garantía del sometimiento de la administración al interés general que aquélla definía.

Desde la perspectiva económica los principios de la ortodoxia liberal imponían dos claras consecuencias:

a) La minimización del gasto público, restringiéndolo al estrictamente indispensable para asegurar la continuidad en el funcionamiento del Estado.

b) El principio del equilibrio presupuestario, de la igualdad entre los ingresos y los gastos. Se entiende que los importes de los estados de gastos $e$ ingresos del presupuesto han de ser equivalentes.

Tanto para los clásicos como en el momento actual existe un concepto más depurado del equilibrio según el cual los presupuestos sólo se presentarían equilibrados cuando el importe de los gastos fuera compensado con partidas de ingresos que no incluyeran el recurso al endeudamiento público o a la emisión de moneda.

En un inicio se entendía que el equilibrio habría de producirse entre gastos $e$ ingresos de carácter ordinario en ambos casos. Las últimas doctrinas estiman, por el contrario, que un equilibrio en el presupuesto, por superávit o por déficit, constituye un requisito necesario para mantener una economía equilibrada en condiciones tan próximas como fuere al pleno empleo.

Cabe señalar que el principio del equilibrio también puede considerarse desde la perspectiva, no de la aprobación del presupuesto, sino de su liquidación. Para los clásicos, se consideraba que el objetivo de equilibrio alcanzaba también a la liquidación del presupuesto. Desde este punto de vista el problema se presenta como de más difícil realización. Puede ser que los ingresos liquidados o los recaudados sean inferiores a las previsiones y también que las superen, ya que respecto a esta última posibilidad deber recordarse que el Estado ha de recaudar los tributos que correspondan a los hechos imponibles efectivamente realizados, con independencia de los cuales hayan sido las previsiones presupuestarias.

\section{LA GESTIÓN PRESUPUESTAL}

Tanto el sector académico, estudiantil y en general la población, deben comprender la problemática de la educación pública y coincidir en puntos comunes para su defensa. Ésta padece actualmente, la falta de políticas de investigación y desarrollo científico, de leyes apropiadas que las orienten al futuro en pleno ejercicio democrático y con autonomía que adecúe la libertad de cátedra con los recursos presupuestarios necesarios.

Por otro lado, la implementación de políticas mal diseñadas de reestructuración del sistema educativo peruano, la modificación de criterios con los que se otorga el presupuesto, la sobre evaluación de las instituciones de educación superior, la restricción de la matrícula, la reducción progresiva de los recursos públicos, explican en gran parte el rezago educativo que existe en el país, y que es tarea nuestra tratar de superarlos.

El debate social y universitario acerca de los aspectos señalados son de vital importancia para el desarrollo universitario, porque definiría la responsabilidad del Estado en la asignación de los recursos que la educación pública requiere para cumplir su rol en el desarrollo de la ciencia y el desarrollo social, y a partir de ello definir el papel de la población en la fiscalización de sus fines y objetivos. 
Tradicionalmente el financiamiento de las universidades públicas ha recaído en las asignaciones presupuestarias que históricamente han sido insuficientes, en cada año -ya se demostró con cifras líneas arriba-, del presupuesto total la mayor parte esta destinado a solventar los gastos corrientes, quedando saldos marginales para los gastos de inversión, lo que genera anualmente un déficit en infraestructura, equipamiento, etc, afectando la modernización de la enseñanza superior. Asimismo, la parte de las remuneraciones contenidas en los gastos corrientes son constantes, es decir, no crean los mecanismos de estímulo y superación docente.

En la búsqueda de una mayor independencia financiera la universidad considera necesario analizar estrategias para generar recursos adicionales al presupuesto; si bien se han realizado importantes esfuerzos aislados, se deben desarrollar acciones que nos permitan articular mejor las iniciativas ante instancias como el Ministerio de Educación, el Parlamento (sus comisiones de educación; presupuesto; y economía) para incrementar el presupuesto institucional. Un enfoque más integrado nos puede llevar a mejores resultados en la búsqueda de fuentes adicionales de financiamiento. Nuestros grupos más consolidados de investigación son una posibilidad, que determina el compromiso de apoyar más intensamente a quién se compromete, suma recursos y obliga a generar una política de apoyos y fortalecimiento de toda el área de investigación. Por otro lado, éstos son los espacios naturales para analizar la pertinencia de los mecanismos y posibilidades de acceso a diversas fuentes de financiamiento. El servicio a la sociedad es otra vía de recursos adicionales, las estructuras académicoadministrativas se han adecuado para dar respuestas ágiles, salvaguardando los principios e intereses de la institución y permitiendo vincularnos con los distintos sectores de la sociedad para alcanzar beneficios mutuos.

Hasta aquí se han planteado respuestas diversas a situaciones que se deben fortalecer o reorientar. A continuación se describen propuestas de índole más global que permitan construir mejores escenarios institucionales.

a) Recuperar el espíritu de la comunidad universitaria, ello significa lograr la integración de grupos de trabajo que encuentren condiciones dignas y justas para habilitarse y llevar a cabo sus actividades con calidad y excelencia académica requeridas. Significa el compromiso de la universidad con sus miembros y de éstos con sus tareas universitarias.

b) Con la intención de recuperar y redefinir el sentido de nuestras acciones en el trabajo universitario es necesario promover y desarrollar programas de formación académica y administrativa. La innovación y recreación del modelo educativo requiere de un esfuerzo permanente de elaboración y reflexión, que aporte a la mejora continua de la calidad académica de nuestras docentes. Al mismo tiempo, implica dar respuesta a la crisis de paradigmas y el vertiginoso avance del conocimiento.

c) El personal administrativo ha de ser igualmente atendido con un programa que les permita reconocer la importancia de su lugar y su trabajo, y que les facilite la actualización técnica y tecnológica que requieren para lograr su inserción creativa en el desarrollo de la institución.

d) Los espacios universitarios han de ser lugares que inviten a reunión, a la convergencia, al diálogo y la discusión académica, que proporcionen la interacción de los miembros y los sectores de la comunidad universitaria. 
e) En relación con la política de educación superior concerniente a la acreditación y certificación, la universidad debe tomar una posición de principio. Los procesos de acreditación de las instituciones de educación superior tienden a su mejoramiento y desarrollo ya que constituyen mecanismos de evaluación externa periódicas de su desempeño académico, planes, programas, condiciones de infraestructura, etc.
Finalmente, la siempre insuficiencia de recursos presupuestarios y financieros en general atentan contra la buena gestión de la universidad, obstaculizando las operaciones de las funciones sustantivas, lo que nos obliga a pugnar por un incremento sustancial de los recursos estatales y a profundizar en el análisis del destino del gasto y a discutir al interior de la UNMSM una política de desarrollo más nítida para sus unidades. 